\title{
Adder (Vipera Berus) bites: a case report and review of the management for emergency medical personnel
}

\author{
M. A. JOHNSTON* \& W. M. TULLETT ${ }^{\dagger}$ \\ Departments of *Accident and Emergency Medicine, and Intensive Therapy, Western \\ Infirmary, Dumbarton Road, Glasgow G11 6NT
}

\section{SUMMARY}

Few doctors working in the accident and emergency (A\&E) department will have had experience in the management of adder (Vipera Berus) bites. While such events are uncommon, and rarely fatal, prompt correct management undoubtedly helps in reducing mortality and morbidity. Various isolated case reports (Watson \& Harland, 1977; Gerard \& Pugh, 1982; Jones \& Clegg, 1985) and larger reviews (Reid, 1976; Pesson \& Irestedt 1981; Hawley, 1988, 1990) have appeared in non A\&E related journals. Following our own recent experience we felt it timely to report our case and review the management.

\section{INTRODUCTION}

The adder (Vepera berus) is the United Kingdom's only indigenous poisonous snake. It is found throughout the country with the exceptions of Orkney, Shetland, the Isle of Man, the Outer Hebrides, Ireland and Iona. The snake prefers dry, sandy heathland and forest edges. In summertime it prefers low-lying, damp meadows. The snake is usually grey or brown in colour although some may be dark red or black. Dark zig zag markings along the back are often seen. A prominent V-shaped marking at the back of the head is a relatively constant feature.

The snake hibernates in winter and resumes feeding in spring. Mating takes place in April or May. Thus bite events may occur anytime between March and October with $62 \%$ of bites occurring in June, July or August (Reid, 1976). Theoretically, bites sustained early in the season carry a higher risk of envenomation

Correspondence: M. A. Johnston, Accident E Emergency Department, Western Infirmary, Dumbarton Road, Glasgow, G11 6NT, U.K. 
due to the higher venom load carried by the adder at this time. In practice, however, the severity of poisoning is unrelated to the month of the bite (Reid, 1976).

There is a concern that the adder population is increasing due to the succession of relatively mild winters and warm summers. This, together with the general increasing trend for outdoor pursuits, may well lead to an increase in the bite rate.

Vipera berus venom is a complex mixture of proteases whose effects are principally cytotoxic and haemotoxic. The cytotoxic element disrupts vascular endothelial linings and this manifests itself clinically as progressive oedema spreading proximally from the site of bite. Progressive cutaneous signs of soft tissue haemorrhage are common. Haemotoxicity is somewhat rarer but coagulation disorders have been documented. Cardiotoxicity, perhaps mediated by a separate element, has been reported and non-specific ST segment changes do signify significant envenomations. Other cardiac effects such as suspected infarction (Brown \& Dewar, 1965 ) and second degree heart block (Moore, 1988) have been described.

\section{CASE REPORT}

A 47-year-old man presented to the A\&E department at $15.30 \mathrm{~h}$ one Sunday in mid-September. He had been bitten by an adder some $30 \mathrm{~min}$ earlier while out walking in open countryside to the north of Glasgow. An accurate description of the snake was obtained.

On initial assessment he was conscious but anxious and distressed by colicky central abdominal pain. He was profoundly nauseated and retched repeatedly. He was peripherally vasoconstricted and sweaty. His blood pressure was measured at $90 / 60$ and his heart rate was 110 beats $\min ^{-1}$ and regular. There were two puncture wounds over the dorsum of his left index proximal interphalangeal joint.

Management at this stage consisted of intravenous infusion of crystalloid solution and the administration of high flow oxygen via face mask. Prochlorperazine $12.5 \mathrm{mg}$ was given intramuscularly. As this was being administered, information on the specific management of adder bites was obtained from the Scottish Poisons Information Centre.

Twenty min after admission, the patient developed facial and intra-oral swelling. This was associated with widespread urticaria. There was no evidence of stridor or bronchospasm. No mention of such symptoms was made on the information obtained from the Poisons Centre. Chlorpheniramine $(10 \mathrm{mg})$ was administered intravenously but no improvement was noted. Due to the fact that the case was an 'unknown quantity' at that time the decision was taken to protect his upper airway using endotracheal intubation. This was done using a rapid sequence induction technique employing $20 \mathrm{mg}$ etomidate and $100 \mathrm{mg}$ suxamethonium. Direct laryngoscopy revealed a red, swollen epiglottis. There was no difficulty with intubation.

The patient was transferred to the intensive therapy unit for ventilation and further monitoring. He was commenced on $100 \mathrm{mg}$ hydrocortisone twice daily, $10 \mathrm{mg}$ chlorpheniramine three times daily and $1 \mathrm{~g}$ Cefotaxime four times daily. He was given a morphine infusion for sedation. 
Initial investigations included full blood count, coagulation screen, arterial blood gas analysis, 12 lead ECG and urea and electrolytes. No abnormalities were detected in any of these initially. Repeat haematology $6 \mathrm{~h}$ later revealed abnormal coagulation (PT 22s, control $15 \mathrm{~s}$, PTT $50 \mathrm{~s}$, control $44 \mathrm{~s})$, a leucocytosis $\left(13.8 \times 10 \mathrm{~L}^{-1}\right.$ with neutrophilia) and a thrombocytopenia (Platelets $84 \times 10 \mathrm{~L}^{-1}$ ). There was no evidence of spontaneous haemorrhage and all abnormalities resolved spontaneously within several days.

Progressive massive haemorrhagic oedema occurred rapidly and extended proximally from the left hand to involve the shoulder girdle region. This was treated using simple elevation. The patient remained stable and was extubated after $36 \mathrm{~h}$ once the oro-facial swelling had settled. He was discharged home 1 week later by which time his left arm had improved dramatically.

\section{DISCUSSION}

This patient provided diagnostic and management difficulties for the staff in the A\&E Department that Sunday afternoon. He was seen initially by a senior registrar in A\&E and, afterwards, by the duty A\&E Consultant, neither of whom had previous experience of the management of such cases. Some useful information was obtained from the Regional Poisons Information Centre and Zagreb antivenom (Regent Lab, London, U.K.) was obtained although not subsequently administered.

The classical features of adder bite envenomations are given in Table 1 and this patient exhibited many of these. We should like to emphasize the possible presence of the anaphylactoid features. Reid (1976) reported swelling of the face, lips and tongue in 12 out of 29 cases of severe poisoning. Three cases of exanthema and two cases of angioneurotic oedema were noted in a review of 136 adder bites in Sweden (Persson \& Irestedt, 1981). Jones \& Clegg (1985) also reported a case of adder bite complicated by angioneurotic oedema. The occurrence of such events emphasizes the dual pathophysiology of envenomation following adder bite, i.e. the direct toxic effects of the venom itself and the predilection for invoking an acute anaphylactoid response. Anaphylactoid responses describes non-lg-E mediated hypersensitivity. In such reactions mast cell degradation occurs either as a result of the direct effect of a substance on the mast cell wall (e.g. as happens with opiates, curare and radiocontrast agents) or as a result of activation of the complement system via the alternative pathway. (Prescott $e t$ al., 1992).

Table 1. Features of adder bite envenomation

Initial episode of collapse and hypotension (self limiting).

Local swelling at site of bite, spreading proximally, becoming haemorrhagic.

Nausea, vomiting and abdominal colic.

Angioneurotic oedema, urticaria, bronchospasm.

Recurrent hypotension.

Spontaneous haemorrhage e.g. from gums (rare). 
Table 2. Indications for administration of Zagreb anti-venom

Persistent hypotension.

Leucocytosis $\left(>20 \times 10 \mathrm{~L}^{-1}\right)$.

ECG changes ( $\mathrm{T}$ wave inversion and/or ST segment depression).

Spontaneous haemorrhage.

Elevated creatinine phosphokinase (indicating myocardial damage).

Massive swelling.

Dose: 2 ampoules of anti-venom diluted in $100 \mathrm{ml}$ of normal saline (suitable for adults and children): rate of administration 15 drops $\min ^{-1}$. NB. Keep adrenaline near to hand.

Such distinction between anaphylactoid and anaphylactic responses are, however, not immediately clinically relevant and emergency management is identical.

We chose to protect the upper airway using endotracheal intubation in anticipation of progressive swelling of the airway. We felt that this was of paramount importance with emphasis on it being performed before the appearance of stridor. There are those who may take exception to the use of the rapid sequence induction technique in this case on the basis that it may have proved impossible to intubate the trachea in the presence of progressive swelling. We would not take issue with this but would emphasize that intubation was performed early in this case. With regard to the management of the other cases cited in the literature, all were managed using either intravenous chlorpheniramine, adrenalin 1:1,000 sc or both plus regular intravenous hydrocortisone.

Should Zagreb anti-venom be used? The general indications are given in Table $2 \leqq$ The current preparation is highly refined and the incidence of acute anaphylactice reactions is very low. The older Pasteur type anti-venom did, however, carry real risks of life-threatening reactions.

\section{CONCLUSIONS}

We would strongly advise A\&E departments to carry detailed literature advising on the management of adder bites. This should include knowledge of where to obtain Zagreb anti-venom locally. We emphasize the dual pathophysiology of envenomation and would advise early consideration of endotracheal intubation in those patients exhibiting allergic type symptoms and signs. Other general supportive measures (which may include blood transfusion in the child) are, of course, of paramount importance.

Specific therapy using Zagreb anti-venom should be used for life-threatening reactions and to reduce local effects from significant limb oedema.

\section{REFERENCES}

Brown R. \& Dewar H. A. (1965) Heart damage following adder bite in England. British Heart Journal 27, 
$144-146$.

Gerrard M. \& Pugh R. (1982) An adder bite with unusual consequences. The Practitioner 226, 527-528. Hawley A. (1988) Adder bites in Aldershot. Journal of the Royal Army Medical Corps 134, 135-137.

Hawley A. (1990) Adder bite in the British Army 1979-1988: a decade of experience. Journal of the Royal Army Medical Corps 136, 114-118.

Jones T. I. \& Clegg W. C. (1985) Management of Vipera berus adder bite. The Practitioner 229, 957-958.

Moore R. S. (1988) Second degree heart block associated with envenomation by Vipera berus. Archives of Emergency Medicine 30, 116-118.

Persson H. \& Irestedt B. (1981) A study of 136 cases of adder bite treated in Swedish hospitals during one year. Acta Medicine Scandanavia 210, 433-439.

Prescott Atkinson T. \& Kaliner M. A. (1992) Anaphylaxis. The Medical Clinics of North America 76, 841-855.

Reid H. A. (1976) Adder bites in Britain. British Medical Journal 2, 153-156.

Watson A. A. \& Harland W. A. (1977) Adder bite fatality in Scotland. Medicine Science Lute 17, 190-192. 